\title{
Increased microenvironment stiffness in damaged myofibers promotes myogenic progenitor cell proliferation
}

Frédéric Trensz ${ }^{1}$, Fabrice Lucien ${ }^{1}$, Vanessa Couture ${ }^{1}$, Thomas Söllrald ${ }^{2}$, Geneviève Drouin ${ }^{1}$, André-Jean Rouleau ${ }^{1}$, Michel Grandbois ${ }^{1,3}$, Gregory Lacraz ${ }^{1,5}$ and Guillaume Grenier ${ }^{1,4^{*}}$

\begin{abstract}
Background: The stiffness of the myogenic stem cell microenvironment markedly influences the ability to regenerate tissue. We studied the effect of damaged myofibers on myogenic progenitor cell (MPC) proliferation and determined whether the structural integrity of the microenvironment contributes to phenotypic changes.

Methods: Individual myofibers were isolated and cultured for 6 days. During this period, the cytoskeleton of myofibers and transcription factors regulating MPC differentiation were characterized by immunostaining. Atomic Force Microscopy (AFM) was performed to measure stiffness of cultured myofibers. Healthy and damaged myofibers, and their associated MPCs, were studied in skeletal muscle from dystrophic and tenotomy mouse models. MPCs were cultured on stiffness-tunable substrates, and their phenotypes were assessed by immunostaining of myogenic transcription factors.

Results: We showed that individual myofibers tend to shrink or collapse when cultured ex vivo starting from day 1 and that this is associated with a marked increase in the number of proliferative MPCs ( $\left.P a x 7^{+} M y o D^{+}\right)$. The myofibers collapsed due to a loss of viability as shown by Evans blue dye uptake and the disorganization of their cytoskeletons. Interestingly, collapsed myofibers in $m d x$ skeletal muscles were similar to damaged myofibers in that they lose their viability, have a disorganized cytoskeleton (actin and a-actinin), and display local MPC $\left(\mathrm{MyoD}^{+}\right)$proliferation at their periphery. In a tenotomy model that causes loss of muscle tension, the cytoskeletal disorganization of myofibers also correlated with the activation/proliferation of MPCs. A deeper analysis of collapsed myofibers revealed that they produce trophic factors that influence MPC proliferation. In addition, collapsed myofibers expressed several genes related to the basal lamina. Immunostaining revealed the presence of fibronectin in the basal lamina and the cytoplasm of damaged myofibers. Lastly, using atomic force microscopy (AFM), we showed that collapsed myofibers exhibit greater stiffness than intact myofibers. Growing MPCs on a 2-kPa polyacrylamide-based substrate, exempt of additional microenvironmental cues, recapitulated proliferation and reduced spontaneous differentiation compared to growth on a 0.5-kPa substrate.

Conclusions: Our results support the notion that collapsed or damaged myofibers increase the structural stiffness of the satellite cell microenvironment, which in addition to other cues such as trophic factors and changes in extracellular matrix composition, promotes the proliferation and maintenance of MPCs, required for myofiber repair.
\end{abstract}

Keywords: Myofiber, Myogenic progenitor cells, Stiffness, Microenvironment

\footnotetext{
*Correspondence: guillaume.grenier@usherbrooke.ca

'Research Centre of the Centre Hospitalier de l'Université de Sherbrooke (CRCHUS), Université de Sherbrooke, Sherbrooke, QC, Canada

${ }^{4}$ Department of Orthopedic Surgery, Faculty of Medicine, Université de Sherbrooke,

3001-12th Avenue North, Sherbrooke J1H 5N4, QC, Canada

Full list of author information is available at the end of the article
}

\section{Biomed Central}

(c) 2015 Trensz et al.; licensee BioMed Central. This is an Open Access article distributed under the terms of the Creative Commons Attribution License (http://creativecommons.org/licenses/by/4.0), which permits unrestricted use, distribution, and reproduction in any medium, provided the original work is properly credited. The Creative Commons Public Domain Dedication waiver (http://creativecommons.org/publicdomain/zero/1.0/) applies to the data made available in this article unless otherwise stated. 


\section{Background}

Satellite cells are quiescent muscle stem cells that play a determinant role in myofiber turnover and postnatal regeneration [1]. Satellite cells are sequestered between the myofiber plasma membrane and the basal lamina [2], and their function is tightly regulated by numerous biochemical and cellular signals in their microenvironment or niche. These consist of subjacent myofiber anchoring; the extracellular matrix (ECM) that sequesters various growth factors; the neighboring cells from the stroma, including immune cells; and the environment of the circulatory system (for a recent review, see [3]). When favorable alterations occur in this complex microenvironment, satellite cells can activate and give rise to proliferative myogenic progenitor cells (MPCs) that repair myofibers, while others return to replenish the satellite cell pool.

Recent evidence has highlighted the importance of the mechanical forces exerted by the ECM in the microenvironment that can modulate the fate and function of satellite cells and MPCs [4-7]. More specifically, the elasticity/stiffness of the microenvironment can modulate in vitro myogenic stem cell renewal, proliferation, differentiation, and regenerative potential $[7,8]$. Boonen et al. showed that substrate elasticity strongly impacts MPC proliferation, while the protein coating influences their differentiation [7]. This is an important finding since it showed for the first time that the biomechanical microenvironment can influence primary MPC proliferation. Skeletal muscle stiffness is mainly determined by the composition of the ECM, notably fibrillar collagen $[9,10]$. First considered as a structural tissue that maintains the integrity of muscle fibers during contraction, it is now well established that the ECM plays a major role in the function of myogenic stem cell and muscle regeneration [11-13]. On the other hand, the mechanical properties of the ECM have an effect on force transmission by muscle fibers to the tendons. Excessive accumulation of ECM (fibrosis) and conditions in which muscle passive stiffness is heightened, such as during myopathy and aging, can impair satellite cell function and muscle regeneration [14-17].

When satellite cells are cultured on traditional plastic dishes, they permanently exit quiescence and acquire a high capacity to proliferate [18]. They concomitantly rapidly lose their self-renewal and regenerative potential, as shown by their limited contribution to muscle regeneration following transplantation $[19,20]$. In contrast, when satellite cells are directly transplanted following isolation or are transplanted in conjunction with subjacent myofibers (a microenvironment component), their potential for regeneration is maintained [21,22]. Interestingly, Gilbert et al. recently showed that culturing myoblasts on substrates of different stiffnesses can influence their self-renewal potential and their capacity to integrate tissues and replenish the stem cell pool when they are transplanted [8]. Other investigators have also shown that changes in ECM composition and/or quality can alter the biomechanical properties of skeletal muscles, which can in turn can modify the proliferation and differentiation potential of MPCs $[7,23,24]$. The loss of regenerative potential by satellite cells in aging, for example, has been attributed more to changes in their microenvironment than to intrinsic modifications $[16,17,25-27]$. This is why we hypothesized that structural changes in damaged myofibers may cause slight changes in the stiffness of the satellite cell microenvironment that may have an impact on their proliferative and differentiation capacities.

We report that individual myofibers cultured in vitro and damaged in vivo myofibers spontaneously shrink or collapse and lose their cytoskeletal organization concomitant with MPC activation/proliferation. We used atomic force microscopy (AFM)-based indentation experiments to show that collapse induced an increase in the stiffness of the satellite cell microenvironment that in turn promoted MPC proliferation. The present study provides new evidence that changes in the biomechanical microenvironment of the anatomical niche of myogenic stem cells have an impact on their behavior.

\section{Methods \\ Animals}

Three-month-old male wild-type (WT) C57Bl/6 (Charles River, Senneville, QC, Canada) mice, Myf5-nLacZ [28] (backcrossed in $\mathrm{C} 57 \mathrm{Bl} / 6$ ) mice, and 8- to 12-month-old C57BL/10ScSn-Dmd/J ( $m d x$ ) (The Jackson Laboratory, Bar Harbor, ME, USA) mice were raised in our animal colony. All animal experiments were approved by the Animal Ethics Committee of Universite de Sherbrooke and were performed in accordance with Canadian Council on Animal Care guidelines (Protocol \#133-14B). Surgeries were performed under anesthesia (isoflurane; Abbott Laboratories, Montreal, QC, Canada). To relieve postoperative pain, the mice were injected subcutaneously with 0.05 to $0.1 \mathrm{mg} / \mathrm{kg}$ of buprenorphine (Temgesic; Schering-Plough, Kenilworth, NJ, USA) 30 min prior to surgery.

\section{Myofiber and myoblast isolation and culture}

Single myofibers from extensor digitorum longus (EDL) muscles were isolated by collagenase digestion as previously described [17], with slight modifications. Briefly, EDL muscles were digested with collagenase for $1 \mathrm{~h}$ at $37^{\circ} \mathrm{C}$ with frequent and gentle agitation. Myofibers were then harvested individually at room temperature using horse serum (HS)-coated Pasteur pipettes. Following several rinses with proliferative medium (Ham's F10 supplemented with $20 \%$ fetal bovine serum (FBS; Hyclone, 
Life Technologies, Little Chalfont, Buckinghamshire, UK), $1 \%$ antibiotics, and $2.5 \mathrm{ng} / \mathrm{ml}$ of bFGF), the myofibers were incubated again with collagenase for $10 \mathrm{~min}$ and were then transferred to proliferative medium and incubated at $37^{\circ} \mathrm{C}$ in a $5 \% \mathrm{CO}_{2}$ humidified incubator for 6 days. Intact and collapsed myofibers were either fixed in $4 \%$ PFA for $10 \mathrm{~min}$, rinsed in PBS, and stored at $4^{\circ} \mathrm{C}$ for immunofluorescence studies or were triturated with HS-coated Pasteur pipettes to isolate peripheral MPCs (or myoblasts). Isolated myoblasts were then enriched and were amplified by four passages in proliferative medium in collagen-coated petri dishes.

\section{Quantitative PCR}

Quantitative PCR (qPCR) was performed as previously described $[25,29]$. Total RNA was extracted using TRIzol ${ }^{\circ}$ (Invitrogen, Burlington, ON, Canada) according to the manufacturer's instructions. The RNA was precipitated with isopropanol and $1 \mu \mathrm{g}$ of glycogen, rinsed with ethanol, and resuspended in RNAse-free water. The RNA was reverse transcribed using RT Superscript II kits (Invitrogen). The qPCR reactions were prepared with PerfeCTa ${ }^{\circ}$ SYBR $^{\circ}$ Green SuperMix (Quanta Biosciences, Gaithersburg, $\mathrm{MD}$, USA). The samples were then placed in a RotorGene 6000 (Corbett Robotics, San Francisco, CA, USA). The qPCR conditions were set as follows: $10 \mathrm{~min}$ at $95^{\circ} \mathrm{C}$; $40 \mathrm{cy}-$ cles of $40 \mathrm{~s}$ at $95^{\circ} \mathrm{C}$ and $40 \mathrm{~s}$ at $56^{\circ} \mathrm{C}$. The results were analyzed using the $2^{-\Delta \Delta C T}$ relative quantification method normalized to the $18 \mathrm{~S}$ housekeeping gene (NR_003286; forward: AGG AAT TGA CGG AAG GGC AC; and reverse: CGA CAT CTA AGG GCA TCA CA). Commercial primers were used for fibronectin (Mm_Fn1_1_SG), collagen IV (Mm_Fn1_1_SG), laminin (Mm_Lama1_1_SG), collagen VI (Mm_Col6a1_1_SG), and IGF-1 (Mm_Igf1_1_SG), all from Qiagen (QuantiTect Primer Assay, Venlo, Limburg, Netherlands).

\section{Preparation of conditioned media from myofibers}

Following EDL muscle digestion, 100 intact and $100 \mathrm{col}-$ lapsed myofibers were harvested, transferred into separate 6-cm petri dishes containing $2.5 \mathrm{ml}$ of myoblast growth medium w/o bFGF (Ham's F10 supplemented with 20\% fetal bovine serum [FBS; Hyclone], and $1 \%$ antibiotic), and cultured at $37^{\circ} \mathrm{C}$ in a $5 \% \mathrm{CO}_{2}$ humidified incubator. After 3 days, conditioned media were collected, centrifuged at $1,200 \mathrm{~g}\left(15 \mathrm{~min}, 4^{\circ} \mathrm{C}\right)$, and filtered $(0.45 \mu \mathrm{m})$ and stored at $4^{\circ} \mathrm{C}$. Conditioned media were used within $24 \mathrm{~h}$.

Cultured primary myoblasts were passaged and plated at 2,000 cells $/ \mathrm{cm}^{2}$ in 48 -well plates that contained myoblast growth medium with bFGF. After $24 \mathrm{~h}$, medium was replaced by conditioned media $(250 \mu \mathrm{l})$, and cells were cultured for 2 days. For proliferation quantification, cells were fixed in 4\% PFA for $10 \mathrm{~min}$ and nuclei stained with DAPI. Five $10 \times$ pictures per well (four wells/ preparation) were randomly taken using an inverted fluorescent microscope (Leica DM-IRE2; Nikon Instruments Inc., Chicago, IL, USA) and were used to count cell numbers.

\section{Tenotomy}

The tibialis anterior (TA) muscles of WT and Myf5$\mathrm{nLacZ}$ mice were exposed by a $1-\mathrm{cm}$ incision in the skin and fascia. The right TA distal tendon was sectioned, and the incision was closed using three stitches. After 10 days, the mice were euthanized, and the TA muscles were harvested for histological studies.

\section{Determination of permeable myofibers in vivo}

To demonstrate the presence of damaged myofibers in vivo, WT and $m d x$ mice were i.p. injected with $1 \%$ $(w / v)$ Evans blue dye (EBD) (Sigma-Aldrich, Oakville, ON, Canada) in sterile PBS as described previously [30]. TA and biceps femoris (BF) muscles were harvested $24 \mathrm{~h}$ after the EBD injection.

\section{Histology and immunofluorescence}

Harvested muscles were immersed in successive PBS baths containing stepped concentrations of sucrose $(5 \%, 15 \%$, and $30 \%)$. The TA and BF muscles were then embedded in OCT:30\% sucrose (O.C.T." Torrance, CA, USA), flashfrozen in isopentane chilled in liquid nitrogen, and stored at $-80^{\circ} \mathrm{C}$ until analyzed. Ten-micrometer sections were cut beginning at the midpoint of the muscles using a cryostat (CM1850; Leica, Canada). To evaluate viability, intact and collapsed myofibers freshly isolated from the EDL muscles of WT mice or after 6 days of culture were immersed in 5\% EBD for $5 \mathrm{~min}$ and were then rinsed with PBS.

For the immunofluorescence experiments, intact and collapsed myofibers isolated from the EDL muscles of WT mice, cell preparations, or $10-\mu \mathrm{m}$-thick TA and BF muscle sections were fixed with $4 \%$ PFA at $4^{\circ} \mathrm{C}$ for $10 \mathrm{~min}$ and were permeabilized in PBS containing 10\% goat serum, $1 \%$ BSA, and $0.2 \%$ Triton $^{\circ} \mathrm{X}-100$ (SigmaAldrich). The cells, myofibers, and tissue sections were incubated with mouse anti-Pax7 (1:2; DSHB, Iowa City, IA, USA), mouse anti-myogenin (1:3; DSHB), mouse anti$\alpha$-actinin (1:1,000; Sigma), rabbit anti-MyoD (1:200; C-20, Santa Cruz, CA, USA), rabbit anti-fibronectin (1:100; Millipore, Billerica, MA, USA), or rabbit anti-Ki67 (1:100; Abcam, Cambridge, UK) primary antibodies or with Alexa 488-conjugated phalloidin (1:1,000; Invitrogen, Canada). After several rinses in PBS-Tween, the samples were incubated with Alexa Fluor ${ }^{\circ}$ 488-conjugated goat anti-mouse IgG (1:1,000) secondary antibody (Invitrogen, Canada). Samples in which the primary antibodies were omitted served as controls. Cell nuclei were labeled with DAPI reagent (Sigma-Aldrich). Following MyoD staining, the BF sections were exposed to light for $48 \mathrm{~h}$ in PBS to bleach 
the fluorescence. An Axioskop 2 phase-contrast/epifluorescence microscope (Carl Zeiss, Inc., Dublin, CA, USA) was used to examine the staining of the tissue sections and myofibers. A Leica DM-IRE2 inverted microscope (Nikon Instruments Inc., USA) was used to examine the cell preparations. The photomicrographs were processed using Image Pro (Media Cybernetics, Rockville, MD, USA) and Simple PCI (Hamamatsu Corporation, Bridgewater, NJ, USA) software.

For X-gal staining, intact and collapsed myofibers isolated from the EDL muscles of Myf5-nLacZ mice as well as the TA muscle sections were fixed with $4 \%$ PFA at $4{ }^{\circ} \mathrm{C}$ for 10 or $60 \mathrm{~min}$. The preparations were then rinsed in $0.1 \mathrm{M}$ phosphate buffer ( $\mathrm{pH}$ 7.3) containing $2 \mathrm{mM} \mathrm{MgCl}_{2}$ and were incubated for a further $30 \mathrm{~min}$ in a detergent solution containing $0.1 \mathrm{M}$ phosphate buffer ( $\mathrm{pH} 7.3$ ), $2 \mathrm{mM}$ $\mathrm{MgCl}_{2}, 5 \mathrm{mM}$ potassium ferricyanide, $5 \mathrm{mM}$ potassium ferrocyanide, $0.01 \%$ sodium deoxycholate, and $0.02 \%$ Nonidet P40 (Sigma-Aldrich). The preparations were then incubated in rinsing solution supplemented with $1 \mathrm{mg} / \mathrm{ml}$ $\mathrm{X}$-gal reagent (Wisent Inc., Saint Jean-Baptiste, QC, Canada) overnight at $37^{\circ} \mathrm{C}$. When the preparations were sufficiently stained, they were rinsed in PBS.

\section{Quantification of myofiber stiffness by atomic force microscopy}

Myofibers were isolated from the EDL muscles of WT mice using the procedure described above. Intact myofibers were either used directly for the stiffness evaluation or were incubated in proliferative medium for 6 days. Intact and collapsed myofibers were transferred into sixwell plates containing a piece of adhesive tape in the bottom of each well. The plates were centrifuged at $400 \mathrm{~g}$ for $10 \mathrm{~min}$ at room temperature to attach the myofibers to the tape. The pieces of tape with the attached myofibers were then transferred into petri dishes and were immersed in PBS for the stiffness evaluation. To evaluate differentiated myogenic cell stiffness, the C2C12 differentiation medium was replaced with PBS. Stiffness was quantified with an AFM-based indentation approach using a custom-built force measurement device similar to the AFM setup described elsewhere [31]. Our setup was mounted on an inverted microscope (Observer Z1; Carl Zeiss, Germany) that allowed the precise positioning of the cantilever tip above the myofiber. Prior to each experiment, the deflection sensitivity was determined in PBS in a plastic petri dish containing no myofibers or myotubes. The nominal spring constant of the silicon nitride cantilever (provided by the manufacturer) was used to convert the photodiode signal into a force value $\left(\mathrm{k}_{\mathrm{nom}}=0.05 \mathrm{~N} / \mathrm{m}\right.$, MLCT; Bruker AFM Probes, Camarillo, CA, USA). The tip of the cantilever was positioned in the middle of each myofiber or myotube, and three forceindentation curves were collected. The data was analyzed using an in-house code in Matlab (MathWorks, Natick, MA, USA) based on the algorithm of Crick et al. [32]. A stepwise Young's modulus was extracted from each forceindentation curve using a modified Hertz model for a foursided pyramidal indenter [33]:

$$
F=\frac{E}{1-v^{2}} \frac{(\tan \alpha)}{\sqrt{2}} \delta^{2},
$$

where $F$ is the indentation force, $E$ the Young's modulus, $v$ the Poisson's ratio (set to 0.5 for isotropic incompressible materials), $\delta$ the indentation, and $\alpha$ the face angle of the pyramid $\left(17.5^{\circ}\right.$ for our cantilever). The mean of three Young's modulus values was calculated for each myofiber or myotube and was used as an expression of stiffness.

\section{Synthesis of stiffness-tunable polyacrylamide gels}

Stiffness-tunable substrates were synthesized using the method described by Tse and Engler [34]. Briefly, 25$\mathrm{mm}^{2}$ round glass coverslips were immersed in $0.1 \mathrm{M}$ $\mathrm{NaOH}$ and were placed on a $80^{\circ} \mathrm{C}$ hot plate until the $\mathrm{NaOH}$ evaporated. The coverslips were coated with 3aminopropyltriethoxysilane (APES), which allows gel adhesion, in a nitrogen-filled tent. The coverslips were rinsed several times with distilled water and then with $0.5 \%$ glutaraldehyde in PBS. Glass slides were treated in parallel with dichlorodimethylsilane (DCDMS) for $5 \mathrm{~min}$. Excess DCDMS was wiped off, and the glass slides were rinsed with distilled water. Gel substrates $(0.5$ and $2 \mathrm{kPa})$ were synthesized by mixing $0.75 \mathrm{ml}$ (7.5\% final concentration) of a $40 \%$ acrylamide solution and $0.3 \% \mathrm{ml}(3.0 \%$ final concentration) of a $2 \%$ bis-acrylamide stock solution with $8.95 \mathrm{ml}$ of distilled deionized water, $1 \mathrm{ml}(10 \%$ final concentration) of a $40 \%$ acrylamide stock solution, and $0.5 \mathrm{ml}$ ( $5 \%$ final concentration) of a $2 \%$ bisacrylamide stock solution with $8.5 \mathrm{ml}$ of distilled deionized water, respectively. The mixtures were degassed under vacuum for $15 \mathrm{~min}$. The substrates were polymerized by adding ammonium persulfate $(1: 100)$ and Temed (1:1,000). A $25 \mu \mathrm{l}$ of gel solution was quickly sandwiched between a pre-treated glass slide and a pretreated coverslip. The polymerized gels were stored at $4^{\circ} \mathrm{C}$ in $40 \%$ ethanol until used. The day before they were used, the gel sandwiches were rinsed in PBS and were collagen coated to improve cell adhesion. MPCs $\left(1,750\right.$ cells $\left./ \mathrm{cm}^{2}\right)$ were plated on the sandwiches and were cultured in proliferative medium. Proliferation was calculated using a Neubauer hemacytometer.

\section{Measurement of cell adherence on stiffness-tunable substrate}

To determine whether polyacrylamide interferes with cell adhesion, MPC proliferation was halted by a $2-\mathrm{h}$ 
treatment with $20 \mu \mathrm{g} / \mathrm{ml}$ of mitomycin-C (Cayman Chemical Company, Ann Arbor, MI, USA). The cells were then rinsed with PBS, trypsinized, centrifuged, resuspended in fresh medium, and plated at 10,000 cells $/ \mathrm{cm}^{2}$ on substrates of different stiffnesses. After $48 \mathrm{~h}$, the cells were fixed with $4 \%$ PFA, stained with DAPI, and counted.

\section{Statistics}

All data are expressed as means \pm SEM. Unpaired student $t$-tests were used to assess statistical significance between groups of fresh and cultured myofibers. A paired $t$-test was used to compare tenotomized muscles with sham-treated contralateral muscles. An F-test of equality of variance was used to compare the periodicity and width of the myofibers. A Kruskal-Wallis test was used to analyze multiple groups. $P<0.05$ was considered to be statistically significant. Statistical values were obtained using GraphPad Prism 6.0 software ${ }^{\mathrm{mm}}$.

\section{Results}

\section{Culturing individual myofibers induces collapse-} associated MPC proliferation

To better understand the muscle regenerative process, we studied MPC regulation using individual myofibers. We cultured individual myofibers isolated from Myf5nLacZ mouse EDL muscles for 6 days in proliferative medium. Since these mice express nuclear $\beta$-galactosidase ( $\beta$-gal) under the control of the Myf5 promoter, which encodes a MPC-specific transcription factor [28], MPCs were localized by X-gal staining. Unlike intact myofibers, we observed a dramatic increase in X-gal staining in collapsed myofibers, which was associated with $\mathrm{Myf5}^{+} \mathrm{MPCs}$, after 6 days (Figure 1A). Interestingly, some myofibers shrank or collapsed, becoming larger and shorter during the first few days of culture (Figure 1A, collapsed myofibers after 6 days). We then determined the time-lapse increase in internal tension over 6 days that led to the collapse phenotype of the cultured myofibers. Intact myofibers collapsed by nearly $50 \%$ after $24 \mathrm{~h}$ in culture and by more than $80 \%$ after 6 days (Additional file 1: Figure S1). Unlike intact myofibers, collapsed myofibers displayed a marked increase in cellular budding on their periphery after 6 days in culture, which is a hallmark of MPC proliferation. In addition, intact myofibers retained their typical striated structure over the entire 6 days of culture, while the collapsed myofibers exhibited impaired internal organization of their actin filaments, as shown by phalloidin staining (Figure 1B). We quantified the number of MPCs in cultured myofibers after 6 days by immunostaining with an antibody directed against the myogenic marker Pax7. Only myofibers containing MPCs $\left(\operatorname{Pax} 7^{+}\right)$were taken into consideration. As expected, based on the cellular budding, there was a significant increase in the number of MPCs in collapsed myofibers compared to intact myofibers (3.5-fold, $P=$ 0.0024; Figure 1C). The number of MPCs in individual myofibers from a given mouse was highly variable and ranged from 0 to more than 300 cells after 6 days (Figure 1C). It is noteworthy that $26.5 \%$ of the collapsed myofibers had more than $100 \mathrm{Pax} 7^{+}$cells per myofiber after 6 days of culture compared to only $11.5 \%$ of the intact myofibers (Figure 1D). These results showed that, following isolation and culture, most myofibers develop a shrunken or collapsed morphology concomitant with an increase in MPC proliferation.

The phenotypes of MPCs in freshly isolated and cultured myofibers were further characterized by Pax7 and MyoD staining, which makes it possible to determine whether the cells are in a quiescent $\left(\mathrm{Pax}^{+} \mathrm{MyoD}^{-}\right)$, proliferative $\left(\mathrm{Pax} 7^{+} \mathrm{MyoD} \mathrm{D}^{+}\right)$, or differentiating $\left(\mathrm{Pax}^{-} \mathrm{MyoD}^{+}\right)$ state (Figure 1E) $[3,25,35,36]$. Our results showed that both freshly isolated intact and collapsed myofibers display a similar proportion of quiescent, proliferative, and differentiating cells, with the quiescent state predominating (more than 90\%). Proliferative and differentiating cells predominated in cultured myofibers, while many fewer cells were in the quiescent state. As expected, the proportion of proliferative cells was significantly higher in collapsed myofibers than in intact myofibers $(P<0.0006)$. As such, the proportion of differentiating cells was also significantly lower $(P<0.006)$, suggesting that the collapse of myofibers promotes MPC proliferation.

\section{The collapse of myofibers induces the proliferation of myogenic progenitor cells in damaged muscle}

To further characterize the collapsed myofibers, we investigated their viability using Evan Blue dye (EBD), which penetrates non-viable and degenerative myofibers [30]. While the intact myofibers remained unstained over the 6 days of culture, the collapsed myofibers were stained blue $\left(\mathrm{EBD}^{+}\right)$(Figure $\left.2 \mathrm{~A}\right)$. The cytoskeletal organization of intact and collapsed myofibers was further characterized using $\alpha$-actinin, a cytoskeletal protein that forms a lattice-like structure and stabilizes the muscle contractile apparatus [37]. Our results showed that both freshly isolated (day 0 ) and cultured (day 6) $\mathrm{EBD}^{-}$myofibers had an organized cytoskeleton, as indicated by the periodicity of the phalloidinstained $\mathrm{F}$-actin and $\alpha$-actinin, while $\mathrm{EBD}^{+}$myofibers were completely disorganized and lacked the characteristic periodicity due the loss of muscle Z-lines (Figure 2A).

Given that dystrophic muscles are characterized by collapsed myofibers and a disorganized cytoskeleton [38-42], we determined whether myofiber collapse was also associated with local proliferation of MPCs in vivo. We injected EBD into $m d x$ mice, a model of Duchenne muscular dystrophy characterized by a high number of 

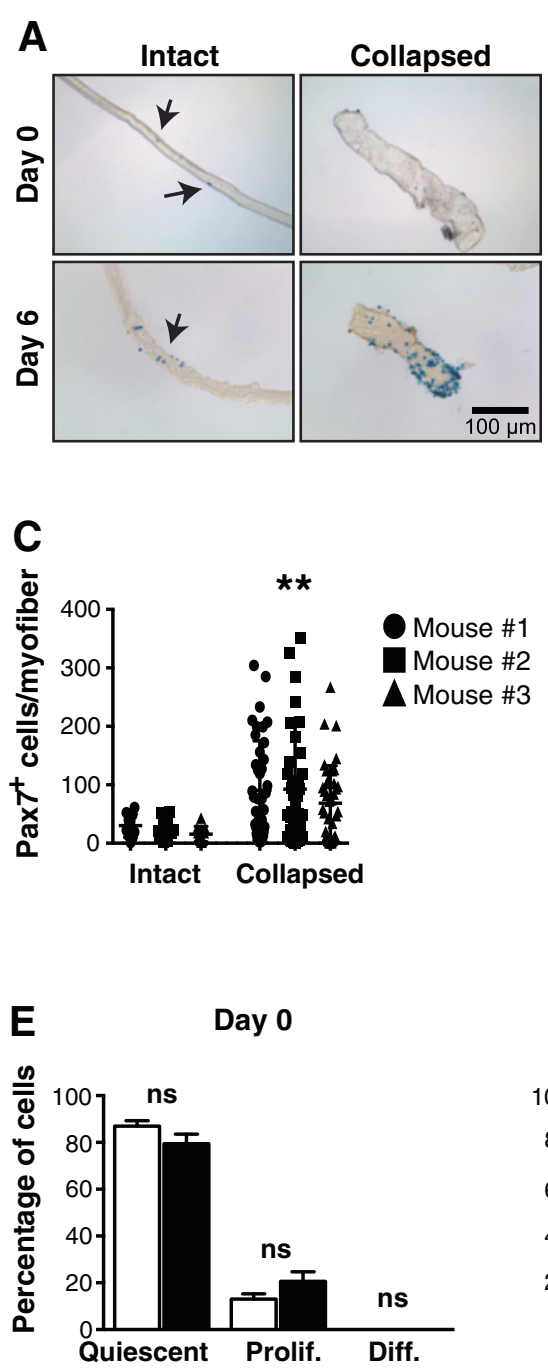

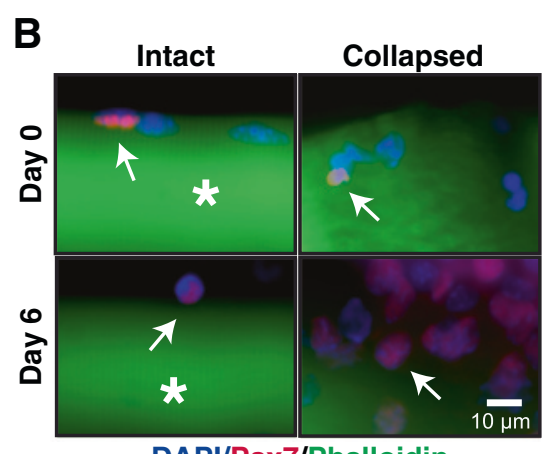

DAPI/Pax7/Phalloidin

D

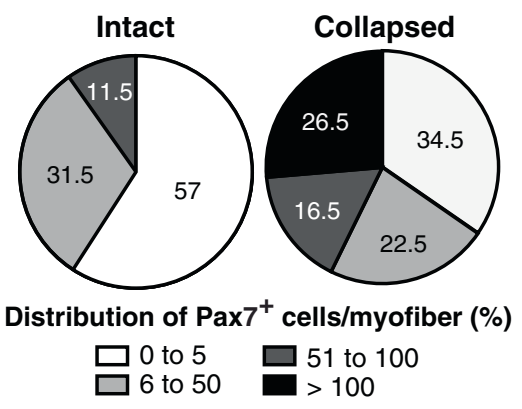

Day 6

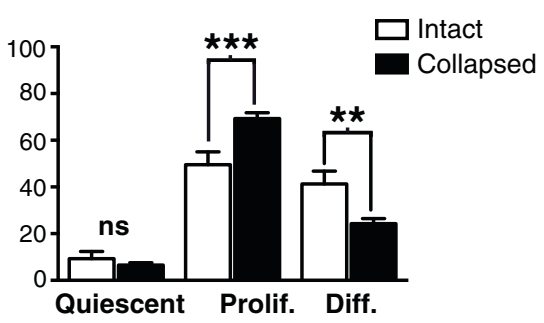

Figure 1 Collapsed individual myofibers induce MPC proliferation. (A) Representative X-gal staining of intact and collapsed myofibers isolated from the EDL muscles of Myf5-nLacZ mice after 0 and 6 days of culture. Arrows indicate Myf5 ${ }^{+}$cells. (B) Representative photomicrographs of intact and collapsed myofibers cultured for 0 and 6 days and immunostained with a Pax7-specific antibody (red) and stained with fluorochrome-conjugated phalloidin and DAPI to reveal actin filaments (F-actin, green) and nuclei (blue), respectively. The arrows indicate MPCs (Pax $7^{+}$cells). (C) Scatter dot plot showing the number of Pax $7^{+}$cells per intact or collapsed myofiber after 6 days of culture. Myofibers from the EDL muscles of three adult WT mice were immunolabeled with a Pax7-specific antibody. Nuclei were stained with DAPI ( $n=0$ to 43 myofibers). ${ }^{*} P=0.0024$ versus intact myofibers. (D) Percentage of the distribution of the number of Pax $7^{+}$cells per intact and collapsed myofiber after 6 days of culture. (E) Bar graphs representing the proportion of MPCs in various differentiation states for intact or collapsed myofibers after 0 and 6 days of culture. Following immunostaining of MPCs with Pax7 and MyoD, the differentiation states were defined in terms of combinations of positive staining: quiescent $\left(\operatorname{Pax} 7^{+} M y o D^{-}\right)$, proliferative $\left(\operatorname{Pax} 7^{+} M y o D^{+}\right)$, and differentiating $\left(\operatorname{Pax} 7^{-} M y o D^{+}\right)$. The results are from three independent experiments. Results are expressed as means \pm SEM. ${ }^{*} P<0.01$; ${ }^{* *} P<0.0001$ versus intact and freshly isolated myofibers.

degenerative myofibers [38]. Histological analyses revealed the presence of sparse $\mathrm{EBD}^{+}$myofibers throughout the muscles (Figure 2B). In addition, we showed that $\mathrm{MyoD}^{+}$ cells are approximately 15 times more numerous near $\mathrm{EBD}^{+}$myofibers than near unstained myofibers (Figure 2B) and that $80 \%$ of them are clustered within $30 \mu \mathrm{m}$ of the $\mathrm{EBD}^{+}$myofibers (Figure 2C), indicating that local cues favor MPC proliferation.

Since collapsed myofibers displayed obvious cytoskeletal disorganization (see Figures $1 \mathrm{~B}$ and $2 \mathrm{~A}$ ), we further characterized the cytoskeletons of damaged $\left(\mathrm{EBD}^{+}\right) m d x$ myofibers. Our observations showed that the F-actin in $\mathrm{EBD}^{+}$myofibers, as revealed by phalloidin staining (Figure 3A), can be classified into three types of organization: 0, organization similar to normal EBD ${ }^{-}$ myofibers; I, disorganization (loss of periodicity); and II, fragmented and/or absence of staining. Based on this classification scheme, we were able to show that there is a significant correlation between the state of actin organization and the number of $\mathrm{MyoD}^{+}$cells associated 

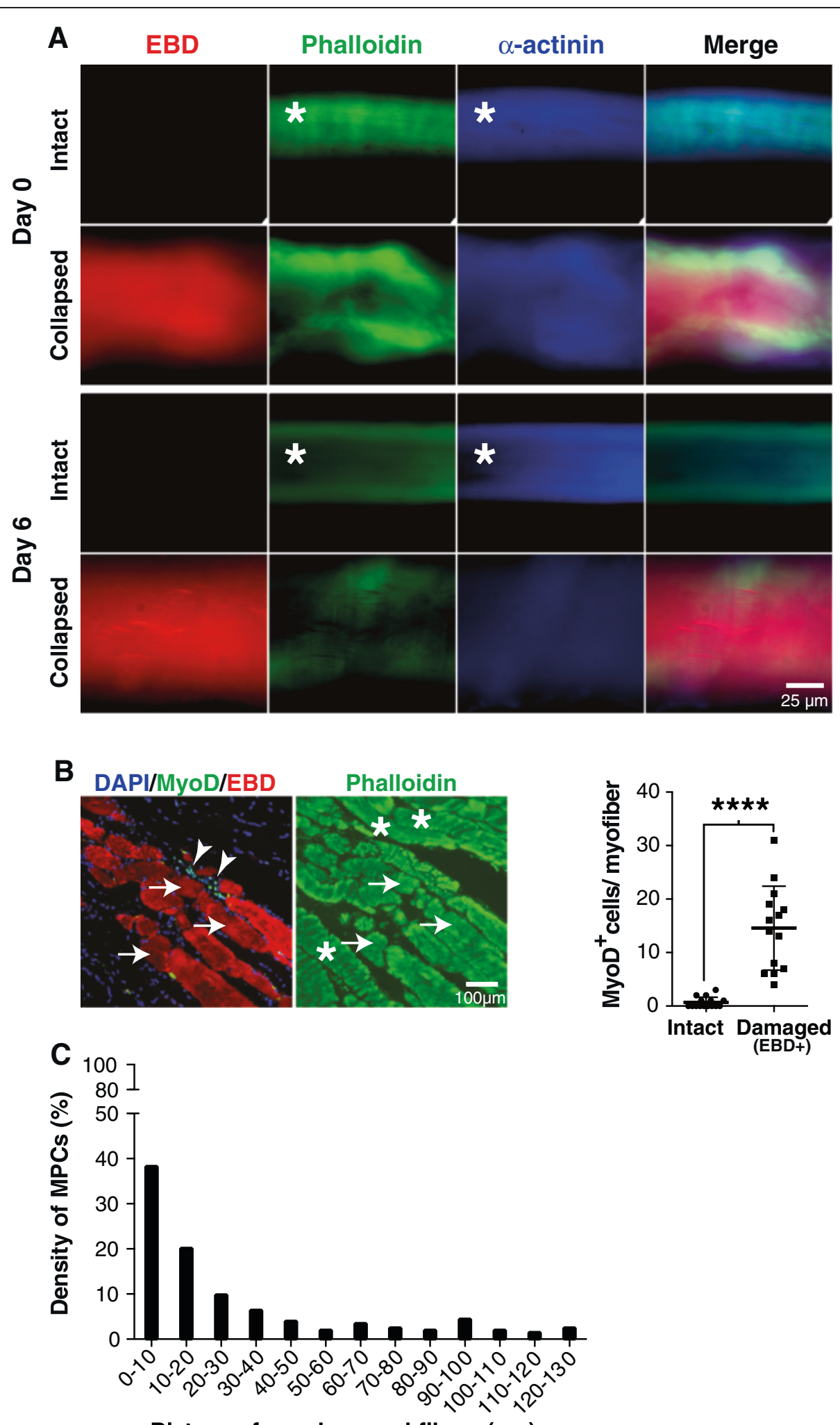

Distance from damaged fibers $(\mu \mathrm{m})$

Figure 2 (See legend on next page.) 
(See figure on previous page.)

Figure 2 The collapse of myofibers induces the proliferation of myogenic progenitor cells in damaged muscle in vivo. (A) Representative photomicrographs of freshly isolated intact myofibers and collapsed myofibers from a C57BI/6 WT mouse ( $n=3$ to 4$)$. After 0 or 6 days of culture, the myofibers were incubated with Evans blue dye (EBD) to stain collapsed myofibers. The myofibers were then immunostained with fluorochrome-conjugated phalloidin to visualize F-actin and with anti-a-actinin to visualize both cytoskeleton proteins. Unlike collapsed myofibers, the intact myofibers displayed periodicity with the phalloidin and a-actinin staining in both the 0 - and 6-day cultures. (B) Representative image of BF muscle longitudinal sections from 8- to 12-month-old $m d x$ mice that had received an intraperitoneal injection of EBD $24 \mathrm{~h}$ prior to euthanasia (left panels). The sections were stained with anti-MyoD (green) and DAPI (blue). The actin cytoskeleton was stained with phalloidin (green) and DAPI (blue). Damaged myofibers were positive for $\mathrm{EBD}^{+}$(red) whereas intact myofibers were $\mathrm{EBD}^{-}$( $n=15$ for intact myofibers and $n=4$ for damaged myofibers; $n=3$ mice). Arrows indicate degenerative EBD ${ }^{+}$myofibers, and arrowheads indicate MyoD ${ }^{+}$cells (activated/proliferative MPCs). Asterisks indicate intact myofibers with the striated pattern of actin. Scatter dot plot showing the number of MyoD ${ }^{+}$cells per myofiber (right panel). Overlay images were mounted in Image Pro and were used to identify MyoD ${ }^{+}$cells. ${ }^{* * *} P<0.00001$ versus control (intact myofibers). (C) Bar graph representing the distance of MPCs from EBD ${ }^{+}$myofibers. After counting the number of cells, distance measurements were obtained by counting the number of $\mathrm{MyOD}^{+}$cells in four different regions per muscle ( $n=6$ muscles). All results are expressed as means \pm SEM.
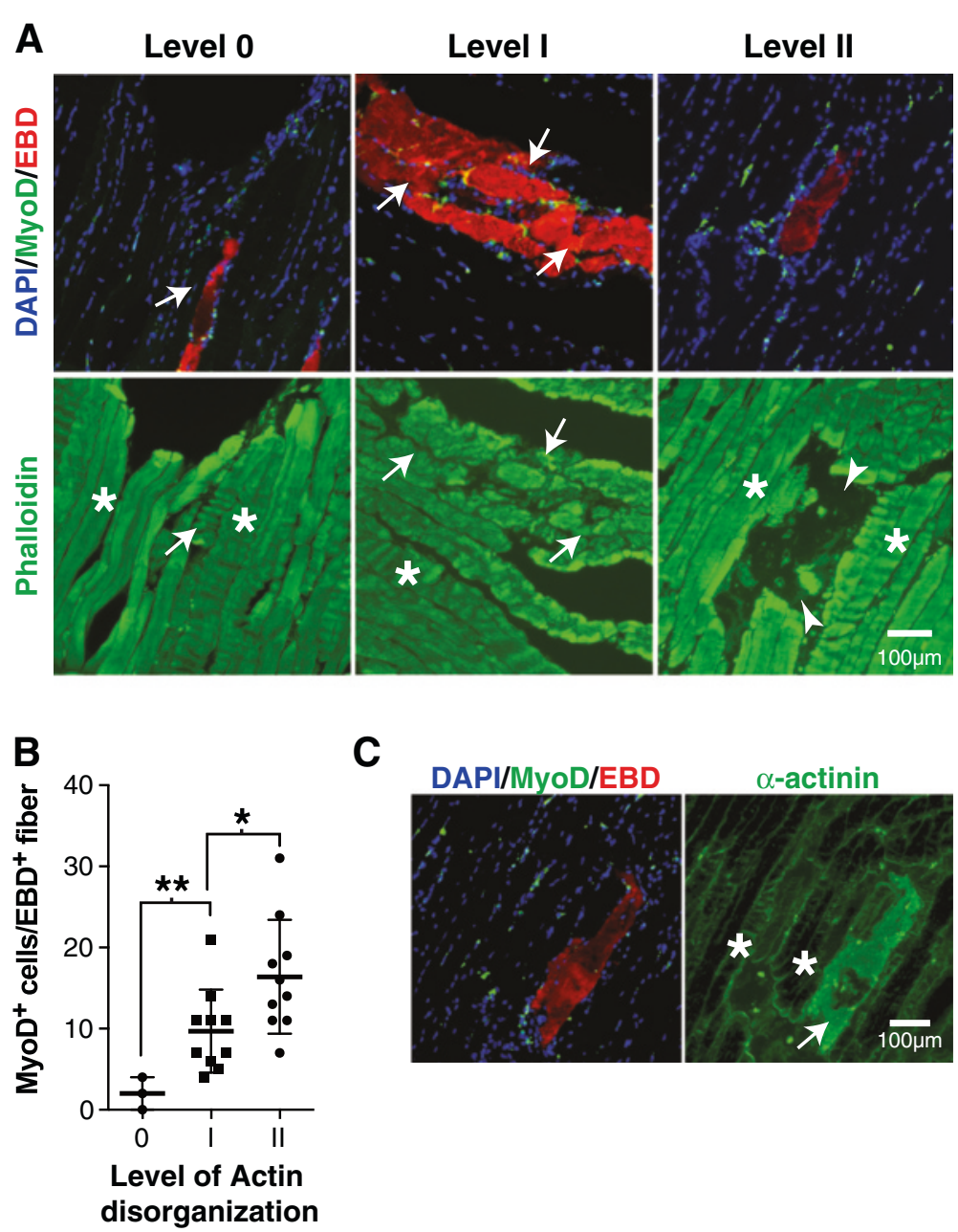

C

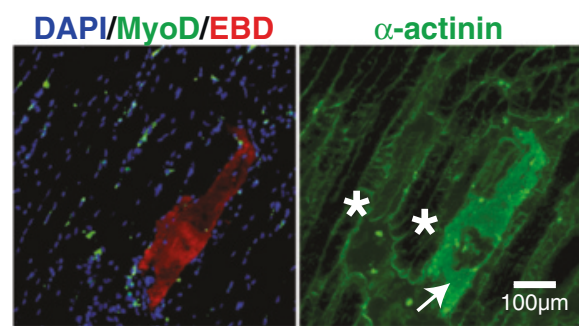

\section{disorganization}

Figure 3 Collapsed myofibers are degenerative cells with a disorganized cytoskeleton. (A) Representative photomicrographs of BF muscle sections showing different levels of actin organization. Level 0 corresponds to organized actin similar to normal EBD- myofibers, level I corresponds to actin disorganization (loss of periodicity and partial fragmentation), and level II corresponds to advanced fragmentation and/or loss of staining. Arrows indicate EBD ${ }^{+}$myofibers, and asterisks indicate intact myofibers. Arrowheads indicate the loss of phalloidin staining (level II). (B) Scatter dot plot quantifying the relative density of $\mathrm{MyoD}^{+}$cells in terms of actin disorganization. These results were obtained from four sections per muscle of BF ( $n=3$ muscles). (C) Representative images of $\mathrm{BF}$ tissue sections showing a-actinin impairment in damaged myofibers compared to intact myofibers. BF sections were stained with anti-a-actinin (green). Nuclei and MPCs were stained with DAPI and anti-MyoD, respectively. The asterisks and arrow indicate normal and impaired a-actinin patterns, respectively. ${ }^{*} P<0.05,{ }^{* *} P<0.01$. All results are expressed as means \pm SEM. 
with $\mathrm{EBD}^{+}$myofibers (Figure 3B), i.e., the higher the level of disorganization the higher the number of $\mathrm{MyoD}^{+}$cells. Interestingly, $\alpha$-actinin staining showed that $100 \%$ of $\mathrm{EBD}^{+}$ myofibers display disorganized $\alpha$-actinin $(n=40)$, as revealed by the loss of periodicity due the loss of muscle Z-lines (Figure 3C). While phalloidin staining (F-actin) is suitable for categorizing the degree of myofiber degeneration (and MPC proliferation), $\alpha$-actinin may be useful for detecting earlier phases in which F-actin is not yet disorganized.

To confirm that the induction of MPC proliferation was caused by the loss of tension in myofibers, we tenotomized the distal tendons of the TA muscles of Myf5nlacZ mice. After 10 days, tenotomized and contralateral control TA muscles were isolated and were stained with $\mathrm{X}$-gal. Gross observations revealed a significant retraction of the tenotomized muscles (approximately $30 \% ; P<$ $0.0001, n=5$ mice) with respect to the contralateral control TA muscles (Figure 4A). Moreover, stronger X-gal staining was observed in the tenotomized TA muscles (Figure 4A). Histological sections were used to quantity MPC proliferation by counting the number of lac $Z^{+}$cells (MPCs) in the same regions of the muscles (Figure 4B). As expected, there was a significant 3 - to 20 -fold increase $(P=0.0313$ to $P<0.0001$; Figure $4 C)$ in the number of proliferating and quiescent MPCs in the tenotomized TA muscles compared to the contralateral control muscles, indicating that a loss of tension also induces MPC proliferation in vivo.

Given their robust retraction over time, we looked at whether the myofibers from these muscle preparations showed evidence of a loss of viability and/or cytoskeletal disorganization compared to the contralateral control muscles. Surprisingly, there were virtually no $\mathrm{EBD}^{+}$myofibers in the muscle preparations. However, immunohistological analyses showed that myofibers from the control muscles had an organized cytoskeleton, as revealed by the periodicity of the $\alpha$-actinin (Figure 4D). On the other hand, myofibers from the tenotomized muscles appeared to have a less organized pattern (Figure 4D). There was a significant difference in the width and periodicity of the $\alpha$-actinin staining of the myofibers in the tenotomized muscles compared to the contralateral muscles (Figure 4E). The myofibers in the tenotomized muscles also contained a larger number of $\mathrm{MyoD}^{+}$cells (Figure 4F).

\section{The microenvironment of collapsed myofibers is} associated with alterations in the ECM and trophic factors The satellite cell microenvironment is profoundly altered following muscle damage and repair [43]. We first determined whether trophic factors secreted by intact or degenerating myofibers can influence MPC proliferation in vitro by performing a proliferation assay using MPCs grown in the presence of conditioned media from intact or collapsed myofibers. Our results showed that MPC proliferation increases slightly but significantly (approximately $13.4 \% ; P<0.0239$ ) when MPCs are grown in conditioned media from collapsed myofibers (Figure 5A). Since IGF-1 is a strong mitotic factor that can be produced by skeletal muscle cells [44], we measured IGF-1 expression in intact and collapsed myofibers and detected a significant 2.4 -fold $(P<0.0002)$ increase in expression in the collapsed myofibers (Figure 5B). These findings suggested that, under these experimental conditions, factors secreted by myofibers can have a significant impact on MPC proliferation.

We then determined whether the expression of recognized basal lamina components is altered in cultured collapsed myofibers compared to intact myofibers. A qPCR gene analysis showed that collagen VI, laminin, and fibronectin, but not collagen IV, expression are significantly higher in collapsed myofibers than in intact myofibers (Figure 5C). Since fibronectin expression increased the most (approximately 224-fold; $P<0.0001$ ) and is known to influence MPC adherence/proliferation, we immunostained (anti-fibronectin) individual cultured intact and collapsed myofibers as well as the skeletal of muscle of $m d x$ mice. As expected, fibronectin was detected at the basal lamina of intact myofibers (arrows). We also observed strong staining around cells (arrowheads) located at the basal lamina as well as irregular staining in the cytoplasm (asterisk) of collapsed myofibers (Figure 5D). These observations were corroborated in the skeletal muscles of WT and $m d x$ mice where fibronectin was mainly observed in the basal lamina of the myofibers. Strikingly, we observed strong, irregular fibronectin staining only in the cytoplasm of $\mathrm{EBD}^{+}$myofibers (asterisk), which was consistent with the results obtained with cultured myofibers (Figure 5E).

\section{Collapsed myofibers increase the stiffness of the myogenic progenitor cell microenvironment and favor the proliferation of myogenic progenitor cells}

Increasing evidence indicates that changes in the mechanical properties of the microenvironment have a major impact on stem cell [45-49] and satellite cell function and behavior $[7,8]$. To determine whether the mechanical microenvironment of collapsed myofibers is altered, we measured the stiffness of intact and collapsed myofibers using an AFM-based indentation approach. The AFM cantilever (black triangle) used to quantify the stiffness of intact (freshly isolated) and collapsed (cultured for 6 days) myofibers can be seen in Figure 6A. There was a 4-fold increase in the stiffness of collapsed myofibers compared to freshly isolated myofibers $(P<$ 0.0001; Figure $6 \mathrm{~B}$ ). In addition, there was no significant difference between freshly isolated and collapsed myofibers on day 0 compared to collapsed myofibers after 


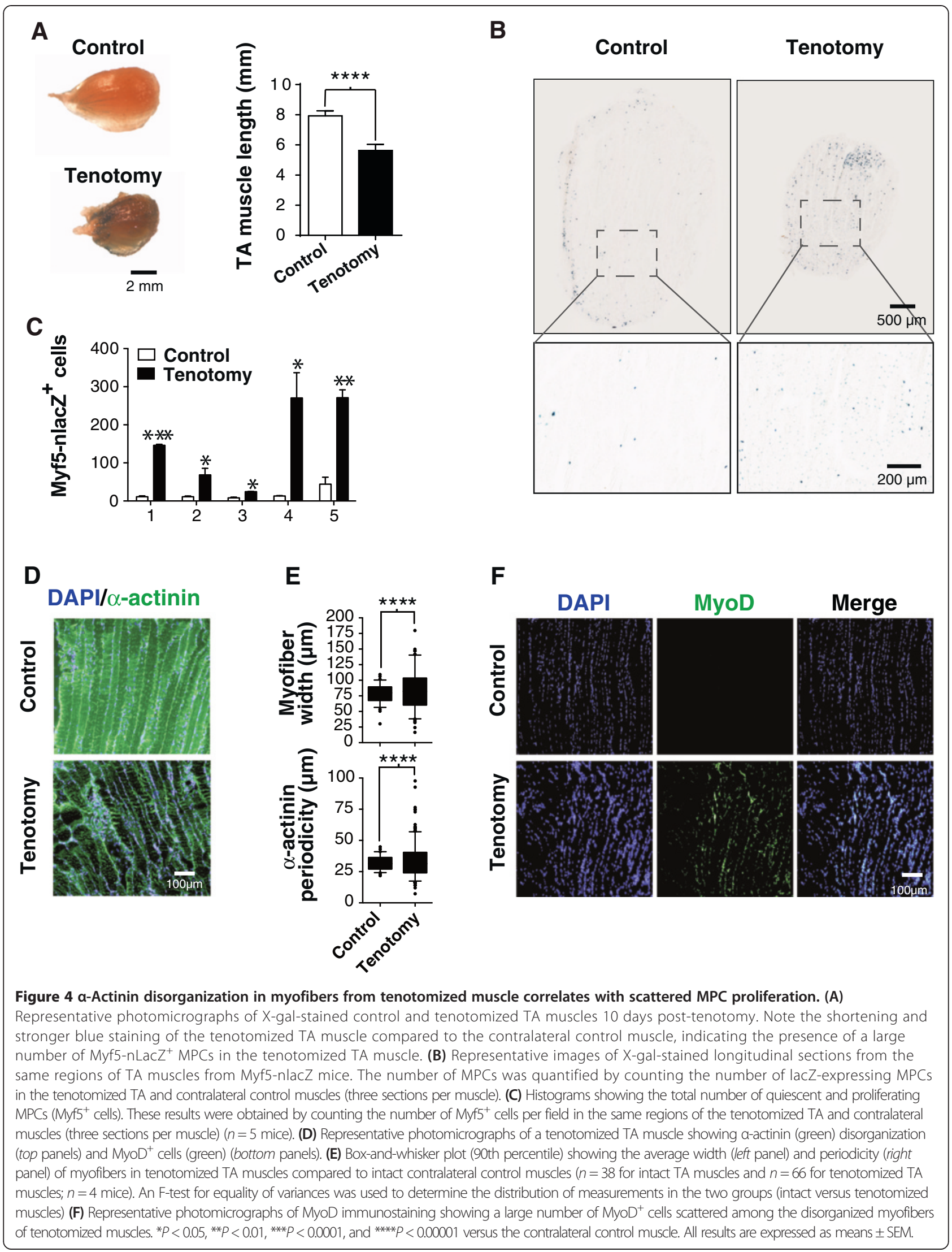



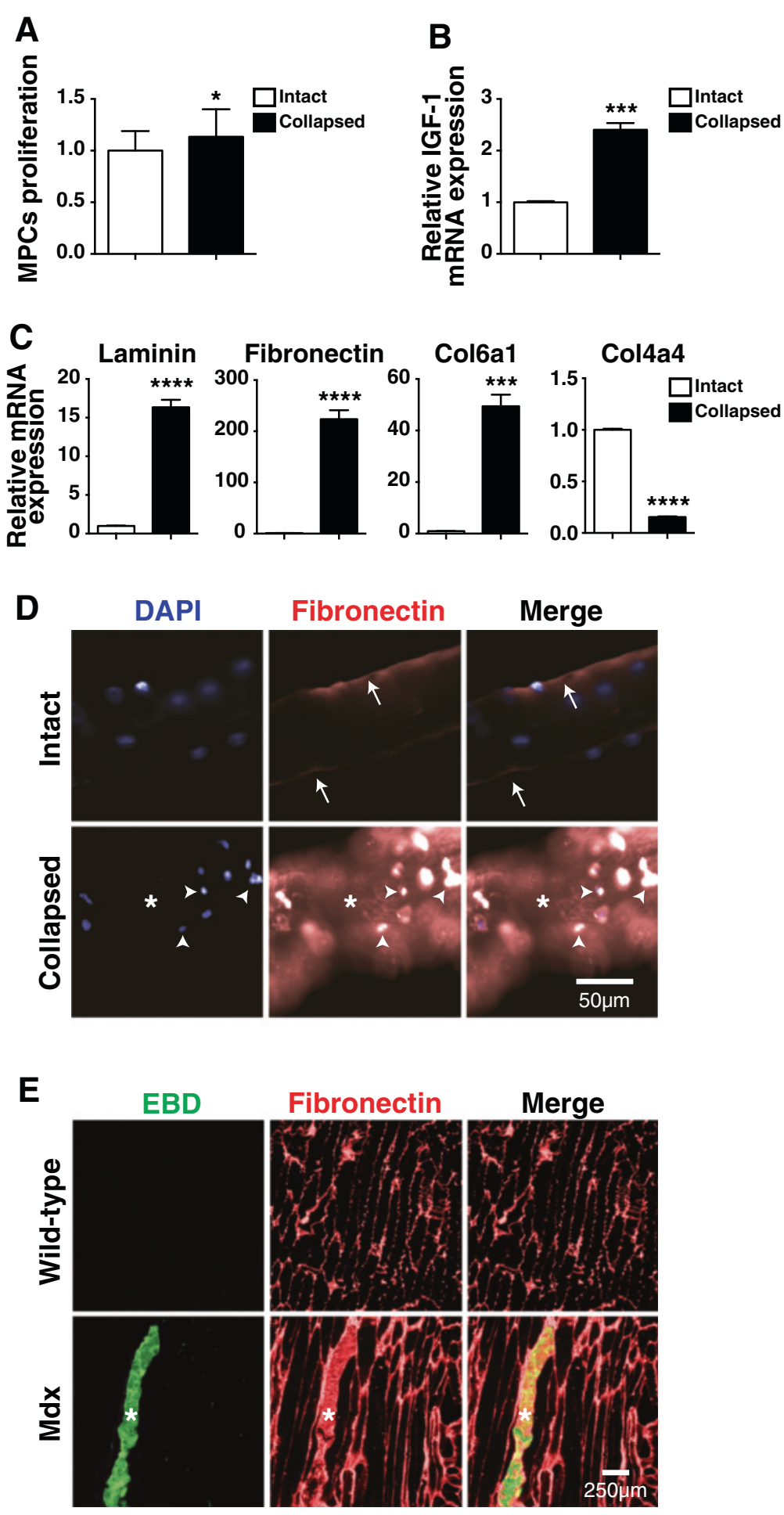


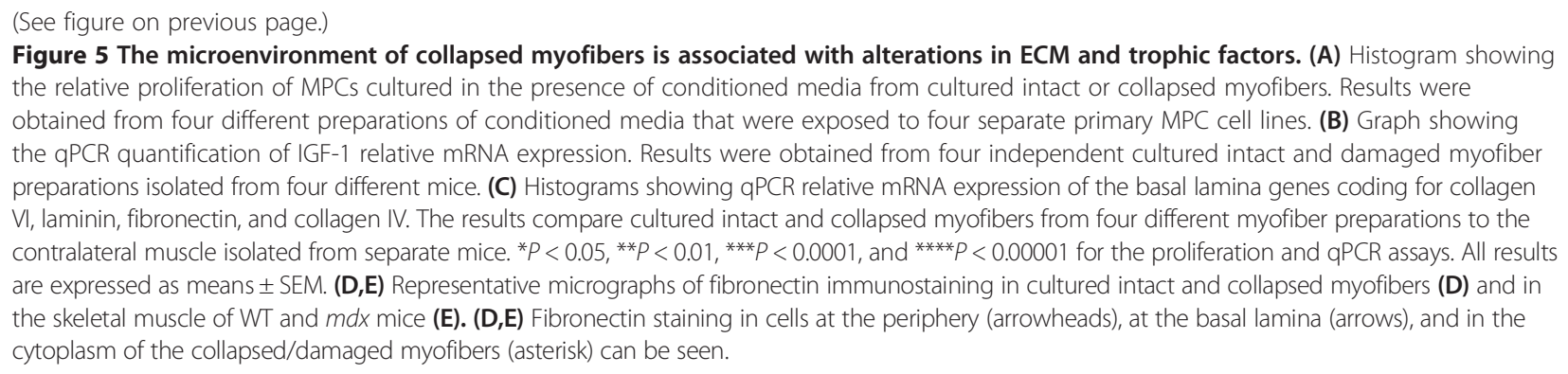

6 days in culture, indicating that myofiber collapse is the main factor contributing to the increase in microenvironment stiffness.

We determined whether the increased proliferation of collapse-associated MPCs resulted from the greater stiffness of the microenvironment by mimicking the stiffness in vitro using stiffness-tunable gel substrates. We used polyacrylamide gels [34] to assess the impact of the stiffness of intact and collapsed myofibers $(0.5$ and $2 \mathrm{kPa}$, respectively) on primary MPC behavior. Exposing MPCs for 4 days to a 2-kPa substrate promoted higher proliferation than exposing them to a $0.5-\mathrm{kPa}$ substrate (1.5-fold increase; $P=0.004$; Figure $6 \mathrm{C}$ ). On the other hand, there was no difference in MPC proliferation after 2 days of culture on the 0.5 - and 2-kPa substrates when the MPCs were pre-treated with mitomycin, a DNA replication blocking agent (Figure 6D), indicating that the increased proliferation of MPCs observed on the 2-kPa substrate was not due to cell detachment. In order to determine the impact of stiffness on MPC proliferation and differentiation, we quantified the expression of Ki67, a nuclear proliferation marker, and myogenin (Myog), a differentiation marker [50], in primary MPCs cultured for 3 days on the $0.5-$ and $2-\mathrm{kPa}$ substrates. The percentage of proliferating $\mathrm{Ki} 67^{+}$cells was significantly higher on the 2$\mathrm{kPa}$ substrate than on the $0.5-\mathrm{kPa}$ substrate (2.4-fold, $P$ $<0.0001$; Figure $6 \mathrm{E}$ ), while the percentage of differentiating $\mathrm{Myog}^{+} \mathrm{MPCs}$ was lower on the $2-\mathrm{kPa}$ substrate than on the $0.5-\mathrm{kPa}$ substrate $(1.9$-fold, $P<0.05$; Figure $6 \mathrm{~F})$. These results indicated that the collapse of myofibers promotes the proliferation of MPCs by increasing myofiber stiffness.

\section{Discussion}

Determining the factors that contribute to the differentiation of satellite cells and their progeny into functional myofibers is essential for understanding skeletal muscle regeneration in aging and for treating muscular pathologies. We studied individual cultured myofibers that collapse in vitro, which promotes the proliferation of MPCs [51,52]. Our results revealed that collapsed myofibers are characterized by a loss of viability and cytoskeletal organization. We also showed in vivo that cytoskeletal disorganization is a key determinant for degenerative myofibers and is concomitant with the local proliferation of MPCs. We further demonstrated, using AFM-based indentation experiments, that myofiber collapse is associated with an increase in the stiffness of the microenvironment of the MPCs. Lastly, tunable-stiffness substrates made it possible to recapitulate the changes in muscle stem cell behavior observed with collapsed myofibers.

Culturing individual myofibers is a valuable method for exploring satellite cell behavior in vitro because it preserves their anatomical niche. It has been used to highlight the asymmetric division and self-renewal of satellites cells induced by the bipolar arrangement of signals arising from subjacent myofibers and the basal lamina [53]. However, a model that reproduces the myofiber damage and alterations to the niche of satellite cells that occur in vivo is lacking. In addition, little is known about the stiffness of the satellite cell microenvironment and its impact on muscle regeneration in vivo.

Collapsed myofibers have been described by Bischoff [51] as hypercontracted in vitro. They are characterized by an extreme shortening of the sarcomeres and an abnormal band pattern. Collapsed myofibers have been observed following extreme eccentric muscle action [54] and in dystrophic muscles [41,42] but, to our knowledge, they have never been investigated in vitro. Unlike traditional primary myogenic cultures prepared from enzymatically dissociated whole muscle, individual myofiber cultures make it possible to study satellite cells and their progeny within their anatomical niche under the basal lamina. We used a Myf5-nLacZ reporter gene and Pax7 immunostaining to show that individual collapsed myofibers display a much larger number of MPCs on their periphery after 6 days of culture than intact myofibers. The large variability in the number of $\operatorname{Pax} 7^{+}$cells on individual collapsed myofibers was likely due to random collapse during culture. The characterization of their differentiation states using Pax7 and MyoD immunostaining indicated that MPCs from both intact and collapsed fresh myofibers are mainly quiescent since they are in their physiological niche $[25,35,36]$. However, when they were cultured, a large proportion became activated and adopted a proliferative state, particularly in collapsed 
A

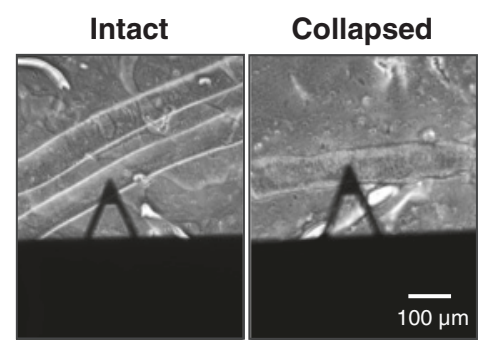

C

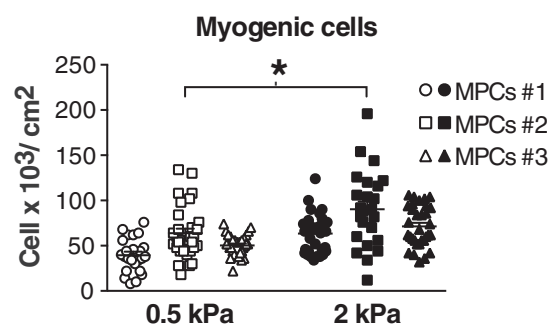

$\mathbf{E}$

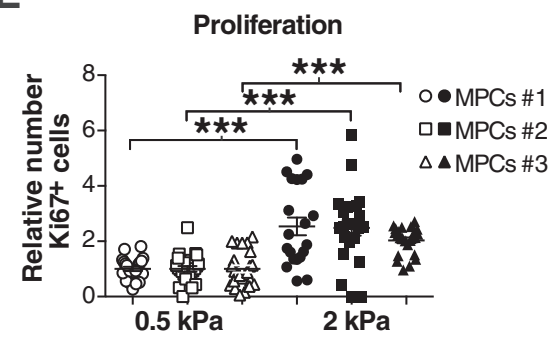

B

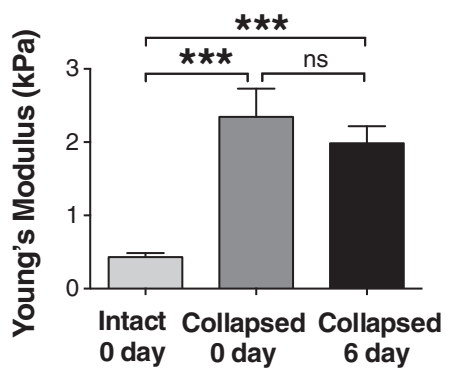

D

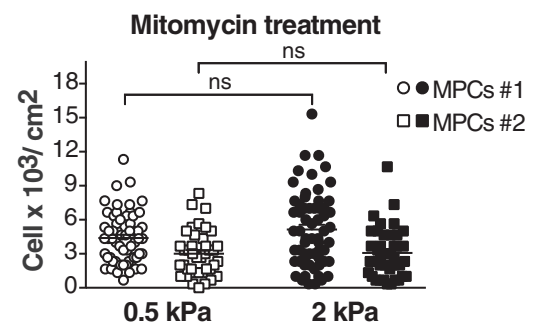

$\mathbf{F}$

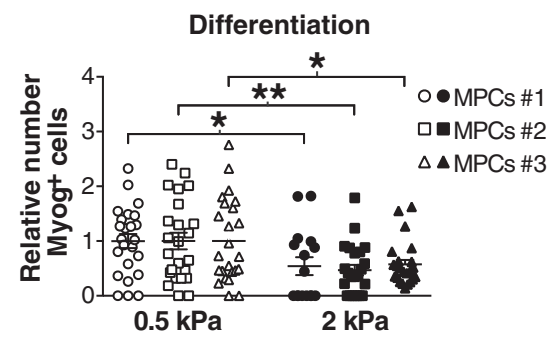

Figure 6 Collapse of myofibers increases the myogenic progenitor cell microenvironment stiffness and maintains cell proliferation.

(A) Representative phase contrast photomicrographs of freshly isolated intact and collapsed myofibers from 3 WT mice in differentiation medium during AFM measurements. The triangular cantilever is shown. (B) Histograms showing the stiffness of isolated intact myofibers ( $n=27)$, collapsed myofibers after 0 days of culture $(n=26)$, and collapsed myofibers after 6 days of culture $(n=22)$. The myofiber stiffness values (average of 3 measurements/myofiber) from 3 independent experiments are expressed as $\mathrm{kPa}$. ${ }^{* *} P<0.0001$ versus intact myofibers on day 0 . (C) Scatter dot plot showing the number of myogenic progenitor cells (MPCs or myoblasts) $/ \mathrm{cm}^{2}$ after 3 days of culture in proliferative medium on the $0.5-$ and $2-\mathrm{kPa}$ substrates. The results were obtained by counting eight fields/well and three wells/substrate $(n=3)$. (D) Scatter dot plot showing the number of $\mathrm{MPCs} / \mathrm{cm}^{2}$ after 3 days of culture in proliferative medium on the 0.5 - or 2-kPa substrates following treatment with mitomycin. Results were obtained by counting 15 fields/well and 4 wells/substrate $(n=2)$. (E) Scatter dot plot showing the percentage of Ki $67^{+}$MPCs after 3 days of culture in proliferative medium on the 0.5 - or $2-\mathrm{kPa}$ substrates. Results were obtained by counting eight fields/well and three wells/substrate $(n=3)$. (F) Scatter dot plot showing the percentage of $\mathrm{Myog}^{+} \mathrm{MPCs}$ after 3 days of culture in proliferative medium on the $0.5-$ and 2-kPa substrates. Results were obtained by counting eight fields/well and three wells/ substrate $(n=3)$. The primary MPC lines were isolated from 3 different mice. Percentages are expressed as relative values of the 0.5 -kPa substrate values. ${ }^{*} P<0.05 ;{ }^{* *} P<0.01 ;{ }^{* * *} P<0.0001$ versus $0.5 \mathrm{kPa}$. Results are expressed as means $\pm \mathrm{SEM}$.

myofibers, indicating that a loss of integrity of the satellite cell substrate influences their activation and favors the proliferation of their progenies.

Sarcolemma disruption and myofiber degeneration are common features of the muscle regeneration process. Previous studies have shown that degenerative and necrotic myofibers are permeable to $\mathrm{EBD}\left(\mathrm{EBD}^{+}\right)$[39]. In the present study, local clusters of proliferative MPCs were closely associated with $\mathrm{EBD}^{+}$myofibers, which was not the case with undamaged $\mathrm{EBD}^{-}$myofibers. Based on phalloidin staining, the $\mathrm{EBD}^{+}$myofibers in $m d x$ mice displayed a disorganized cytoskeleton, which could be categorized according to their level of organization. Interestingly, the number of MPCs was proportional to the disorganization state of the actin cytoskeleton, suggesting that that various states may be correlated with the sequence of myofiber degeneration, where the complete loss of actin staining represents the ultimate state. We also showed that $\alpha$-actinin, a cytoskeletal protein that is essential for the stability of the contractile 
apparatus responsible for the transmission of the force generated to the extracellular matrix through integrins [37,55-57], is also disorganized in the $\mathrm{EBD}^{+}$myofibers, as shown by the lack of periodicity typical of structured sarcomeres. This suggested that $\alpha$-actinin disorganization may precede $\mathrm{F}$-actin disorganization, since the organization of the F-actin of a proportion of $\mathrm{EBD}^{+}$myofibers was similar to that of undamaged myofibers.

Since myofiber collapse or shortening appeared to be a key for MPC activation/proliferation, we determined whether MPC proliferation is affected by traumatic muscle shortening. We used a tenotomy model to show that the number of MPCs is significantly higher in tenotomized than in contralateral control muscles. This increase in MPC proliferation confirmed previous findings with respect to $\left[{ }^{3} \mathrm{H}\right]$ thymidine incorporation showing that TA tenotomy promotes the proliferation of stromal and myogenic cells [58]. Unlike $m d x$ mice in which MPCs proliferate locally around $\mathrm{EBD}^{+}$myofibers, there were virtually no $\mathrm{EBD}^{+}$myofibers in the tenotomized muscles, and the MPCs were rather scattered throughout the tissue, with a few clusters of MPCs. Despite the absence of degenerating $\mathrm{EBD}^{+}$myofibers, the vast majority of myofibers displayed generalized disorganization, as shown by the loss of width uniformity. In addition, F-actin and $\alpha$-actinin staining revealed that most of the myofibers had a disorganized cytoskeleton as shown by the lack of periodicity. As such, in addition to collapsed necrotic myofibers, the physiological loss of myofiber tension in vivo appeared to be sufficient to induce the activation and proliferation of MPCs in vivo.

Changes in the satellite cell niche microenvironment directly impact MPC activities [1,3,43]. This is based on a number of seminal studies showing that Notch, IGF-1, FGF2, Wnt, and TGF $\beta$ are involved in the MPC niche and the alteration of MPC activity (reviewed in [59]). Likewise, M-cadherin, a highly expressed cell adhesion molecule in satellite cells, is also involved in MPC activation [60,61], attachment, and fusion during prenatal myogenesis [62]. In the present study, we showed that trophic factors produced by collapsed/damaged myofibers and their MPCs favor MPC proliferation in vitro. In fact, IGF-1 expression was higher in collapsed myofibers, which corroborated previous reports that IGF-1 secretion increases in differentiated skeletal muscle cells undergoing biomechanical stimulation (stretching) [44]. Furthermore, Wnt signaling, which dictates the fate of satellite cells by controlling their expansion, is highly dependent on the binding of the ECM glycoprotein fibronectin to syndecan-4 [63]. Interestingly, fibronectin, which plays an important role during wound healing [64] and muscle regeneration [65,66], was highly expressed in damaged myofibers both in vitro and in vivo. Altogether, our findings highlight the complex nature of the interactions between biochemical factors and the ECM in the MPC microenvironment. This was especially true for MPCs cultured on plastic petri dishes, which are dissociated from their biochemical and biomechanical microenvironments and which invariably lose their stemness and regenerative potential $[19,20]$.

A previous study using AFM-based indentation experiments to determine the stiffness value of skeletal muscle reported a Young's modulus of approximately $12 \mathrm{kPa}$ [67]. However, this study used skeletal muscle slices composed of multiple structures such as ECM layers that can have an impact on elastic properties. Myofiber bundles are four times stiffer when ECM components are present than individual myofibers that have been stripped of their ECM [9]. Moreover, absolute stiffness values determined by AFM indentation strongly depend on the experimental parameters, model, and parameters used to analyze the results [68].

Interestingly, our AFM-based experiments with individual myofibers revealed that the stiffness values of intact myofibers are four times lower than those of collapsed myofibers ( 0.5 versus $2.0 \mathrm{kPa})$. When the stiffness values were recapitulated in gel substrates, the 2$\mathrm{kPa}$ environment promoted the proliferation of MPCs and inhibited their differentiation, maintaining MPCs in a proliferative state. This was in agreement with previous work showing that MPC proliferation is strongly influenced by elasticity while their differentiation is modulated by the protein coating [7]. Studying MPC behavior is of the utmost importance in such contexts since the mechanical microenvironment of MPCs also has a direct impact on their regenerative potential following transplantation [8]. For example, the engraftment scores of MPCs grown on a 12-kPa substrate for 1 week are significantly higher than those of MPCs grown on 2-, 42-, and $1 \times 10^{6}-\mathrm{kPa}$ substrates, which correspond to brain, cartilage, and plastic petri dish stiffnesses, respectively [8]. While stiffness appears to be a major contributor to the modulation of satellite cell and MPC behavior, further studies will be required to understand the cross-talk between the matrix (mechanotransduction) and the cytokine/growth factors in the microenvironment of degenerative/regenerative myofibers.

\section{Conclusions}

Our results provided new evidence that minor biomechanical alterations in the microenvironment, such as stiffness, are sufficient to directly impact the proliferative and differentiation capacities of muscle stem cells. In essence, they reinforce the role of microenvironmental cues such as mechanical constraints and local factors in MPC behavior during physiological muscle repair, muscle regenerative disorders, and aging. 


\section{Additional file}

Additional file 1: Figure S1. The proportion of collapsed myofibers increases as a function of time in culture. Graph displaying the percentage of collapsed myofibers over a period of 6 days in culture $(n=5)$. Over $80 \%$ of the myofibers were collapsed on day 6 .

\section{Abbreviations}

BF: biceps femoris; ECM: extracellular matrix; EDL: extensor digitorum longus; kPa: kilo Pascal; MPCs: myogenic progenitor cells; TA: tibialis anterior.

\section{Competing interests}

The authors declare that they have no competing interests.

\section{Authors' contributions}

$F T, T S, F L, G D$, and GG formulated and designed the experiments. FT, TS, FL, $A J R, G D$, and VC performed the experiments. FT, VC, FL, GD, GL, and GG analyzed the data. FT, MG, and GG contributed reagents, materials, and analytical tools. FT, GL, FL, and GG wrote the paper. All authors read and approved the final manuscript.

\section{Acknowledgements}

We are grateful to Dr. Anthony Scimè for critically reading the manuscript, Dr. Michael Rudnicki for providing the Myf5-nLacZ mice, Gene Bourgeau for proofreading the manuscript, Marc-Antoine Lauzon for the statistical analyses, and Jennifer Downey for editing the figures. This work was supported by grants from the Canadian Institutes of Health Research (CIHR), the Canada Foundation for Innovation (CFI), and the Fonds de Recherche du Québec - Santé (FRQS). FT received a scholarship from FORMSAV and the Fondation pour la Recherche et I'Enseignement en Orthopédie de Sherbrooke (FREOS). GL received a post-doctoral scholarship from CIHR. GG received a New Investigator Award from FRQS.

\section{Author details}

'Research Centre of the Centre Hospitalier de I'Université de Sherbrooke (CRCHUS), Université de Sherbrooke, Sherbrooke, QC, Canada. ${ }^{2}$ Department of Electrical and Computer Engineering, Faculty of Engineering, Université de Sherbrooke, Sherbrooke, QC, Canada. ${ }^{3}$ Department of Pharmacology, Faculty of Medicine, Université de Sherbrooke, Sherbrooke, QC, Canada. ${ }^{4}$ Department of Orthopedic Surgery, Faculty of Medicine, Université de Sherbrooke, 3001-12th Avenue North, Sherbrooke J1H 5N4, QC, Canada. ${ }^{5}$ New address: Hubrecht Institute, University Medical Center Utrecht, Utrecht, The Netherlands

\section{Received: 15 August 2014 Accepted: 19 January 2015}

\section{Published online: 17 February 2015}

\section{References}

1. Yin H, Price F, Rudnicki MA. Satellite cells and the muscle stem cell niche. Physiol Rev. 2013;93:23-67.

2. Mauro A. Satellite cell of skeletal muscle fibers. J Biophys Biochem Cytol. 1961;9:493-5.

3. Motohashi N, Asakura A. Muscle satellite cell heterogeneity and self-renewal. Front Cell Dev Biol. 2014;2:00001.

4. Wang N, Tytell JD, Ingber DE. Mechanotransduction at a distance: mechanically coupling the extracellular matrix with the nucleus. Nat Rev Mol Cell Biol. 2009;10:75-82.

5. Geiger B, Spatz JP, Bershadsky AD. Environmental sensing through focal adhesions. Nat Rev Mol Cell Biol. 2009;10:21-33.

6. Cosgrove BD, Sacco A, Gilbert PM, Blau HM. A home away from home: challenges and opportunities in engineering in vitro muscle satellite cell niches. Differentiation. 2009;78:185-94

7. Boonen KJ, Rosaria-Chak KY, Baaijens FP, van der Schaft DW, Post MJ. Essential environmental cues from the satellite cell niche: optimizing proliferation and differentiation. Am J Physiol Cell Physiol. 2009:296:C1338-45.

8. Gilbert PM, Havenstrite KL, Magnusson KE, Sacco A, Leonardi NA, Kraft P, et al. Substrate elasticity regulates skeletal muscle stem cell self-renewal in culture. Science. 2010;329:1078-81.

9. Meyer GA, Lieber RL. Elucidation of extracellular matrix mechanics from muscle fibers and fiber bundles. J Biomech. 2011:44:771-3.
10. Wood LK, Kayupov E, Gumucio JP, Mendias CL, Claflin DR, Brooks SV. Intrinsic stiffness of extracellular matrix increases with age in skeletal muscles of mice. J Appl Physiol. 2014;1985:363-9.

11. Osses N, Brandan E. ECM is required for skeletal muscle differentiation independently of muscle regulatory factor expression. Am J Physiol Cell Physiol. 2002;282:C383-94.

12. Gillies AR, Lieber RL. Structure and function of the skeletal muscle extracellular matrix. Muscle Nerve. 2011:44:318-31.

13. Calve $\mathrm{S}$, Odelberg SJ, Simon HG. A transitional extracellular matrix instructs cell behavior during muscle regeneration. Dev Biol. 2010;344:259-71.

14. Kragstrup TW, Kjaer M, Mackey AL. Structural, biochemical, cellular, and functional changes in skeletal muscle extracellular matrix with aging. Scand J Med Sci Sports. 2011:21:749-57.

15. Alnaqeeb MA, Al Zaid NS, Goldspink G. Connective tissue changes and physical properties of developing and ageing skeletal muscle. J Anat. 1984;139(Pt 4):677-89.

16. Brack AS, Conboy MJ, Roy S, Lee M, Kuo CJ, Keller C, et al. Increased Wnt signaling during aging alters muscle stem cell fate and increases fibrosis. Science. 2007;317:807-10.

17. Trensz F, Haroun S, Cloutier A, Richter MV, Grenier G. A muscle resident cell population promotes fibrosis in hindlimb skeletal muscles of mdx mice through the Wnt canonical pathway. Am J Physiol Cell Physiol. 2010;299(5):C939-47. doi: 10.1152/ajpcell.00253.2010.

18. Shefer G, Van de Mark DP, Richardson JB, Yablonka-Reuveni Z. Satellite-cell pool size does matter: defining the myogenic potency of aging skeletal muscle. Dev Biol. 2006;294:50-66

19. DiMario JX, Stockdale FE. Differences in the developmental fate of cultured and noncultured myoblasts when transplanted into embryonic limbs. Exp Cell Res. 1995:216:431-42.

20. Gussoni E, Pavlath GK, Lanctot AM, Sharma KR, Miller RG, Steinman L, et al. Normal dystrophin transcripts detected in Duchenne muscular dystrophy patients after myoblast transplantation. Nature. 1992;356:435-8.

21. Collins CA, Olsen I, Zammit PS, Heslop L, Petrie A, Partridge TA, et al. Stem cell function, self-renewal, and behavioral heterogeneity of cells from the adult muscle satellite cell niche. Cell. 2005:122:289-301.

22. Sacco A, Doyonnas R, Kraft P, Vitorovic S, Blau HM. Self-renewal and expansion of single transplanted muscle stem cells. Nature. 2008:456:502-6.

23. Urciuolo A, Quarta M, Morbidoni V, Gattazzo F, Molon S, Grumati P, et al Collagen VI regulates satellite cell self-renewal and muscle regeneration. Nat Commun. 2013:4:1964

24. Gattazzo F, Urciuolo A, Bonaldo P. Extracellular matrix: a dynamic microenvironment for stem cell niche. Biochim Biophys Acta. 2014;1840:2506-19.

25. Scime A, Desrosiers J, Trensz F, Palidwor GA, Caron AZ, Andrade-Navarro MA, et al. Transcriptional profiling of skeletal muscle reveals factors that are necessary to maintain satellite cell integrity during ageing. Mech Ageing Dev. 2010;131:9-20.

26. Conboy IM, Conboy MJ, Wagers AJ, Girma ER, Weissman IL, Rando TA. Rejuvenation of aged progenitor cells by exposure to a young systemic environment. Nature. 2005;433:760-4.

27. Chakkalakal JV, Jones KM, Basson MA, Brack AS. The aged niche disrupts muscle stem cell quiescence. Nature. 2012;490:355-60.

28. Tajbakhsh S, Bober E, Babinet C, Pournin S, Arnold H, Buckingham M. Gene targeting the myf-5 locus with nlacZ reveals expression of this myogenic factor in mature skeletal muscle fibres as well as early embryonic muscle. Dev Dyna. 1996;206:291-300.

29. Downey J, Lauzier D, Kloen P, Klarskov K, Richter M, Hamdy R, et al. Prospective heterotopic ossification progenitors in adult human skeletal muscle. Bone. 2015;71:164-70.

30. Hamer PW, McGeachie JM, Davies MJ, Grounds MD. Evans blue dye as an in vivo marker of myofibre damage: optimising parameters for detecting initial myofibre membrane permeability. J Anat. 2002;200:69-79.

31. Cuerrier CM, Benoit M, Guillemette G, Gobeil Jr F, Grandbois M. Real-time monitoring of angiotensin II-induced contractile response and cytoskeleton remodeling in individual cells by atomic force microscopy. Pflugers Arch. 2009;457:1361-72

32. Crick SL, Yin FC. Assessing micromechanical properties of cells with atomic force microscopy: importance of the contact point. Biomech Model Mechanobiol. 2007:6:199-210

33. Bilodeau GG. Regular pyramid punch problem. J appl Mech. 1992;59:519-23. 
34. Tse JR, Engler AJ. Preparation of hydrogel substrates with tunable mechanical properties. Curr Protoc Cell Biol. 2010. Jun; Chapter 10:Unit 10.16. doi:10.1002/0471143030.cb1016s47.

35. Zammit PS, Golding JP, Nagata Y, Hudon V, Partridge TA, Beauchamp JR. Muscle satellite cells adopt divergent fates: a mechanism for self-renewal? J Cell Biol. 2004:166:347-57.

36. Zammit PS, Partridge TA, Yablonka-Reuveni Z. The skeletal muscle satellite cell: the stem cell that came in from the cold. J Histochem Cytochem. 2006:54:1177-91.

37. Sjoblom B, Salmazo A, Djinovic-Carugo K. Alpha-actinin structure and regulation. Cell Mol Life Sci. 2008;65:2688-701.

38. Matsuda R, Nishikawa A, Tanaka H. Visualization of dystrophic muscle fibers in mdx mouse by vital staining with Evans blue: evidence of apoptosis in dystrophin-deficient muscle. J Biochem. 1995;118:959-64.

39. Straub V, Rafael JA, Chamberlain JS, Campbell KP. Animal models for muscular dystrophy show different patterns of sarcolemmal disruption. J Cell Biol. 1997:139:375-85.

40. Klyen BR, Shavlakadze T, Radley-Crabb HG, Grounds MD, Sampson DD. Identification of muscle necrosis in the mdx mouse model of Duchenne muscular dystrophy using three-dimensional optical coherence tomography. J Biomed Opt. 2011;16:076013.

41. Cozzi F, Cerletti M, Luvoni GC, Lombardo R, Brambilla PG, Faverzani S, et al. Development of muscle pathology in canine X-linked muscular dystrophy. II. Quantitative characterization of histopathological progression during postnatal skeletal muscle development. Acta Neuropathol. 2001;101:469-78.

42. Punkt K, Schering S, Fritzsche M, Asmussen G, Minin EA, Samoilova VE, et al. Fibre-related nitric oxide synthase (NOS) in Duchenne muscular dystrophy. Acta Histochem. 2007;109:228-36.

43. Trensz F, Scimè A, Grenier G. Skeletal muscle engineering: the need for of a suitable niche. In: Bernstein HS, editor. Tissue engineering in regenerative medicine. New York: Springer; 2011.

44. Perrone $\mathrm{CE}$, Fenwick-Smith D, Vandenburgh HH. Collagen and stretch modulate autocrine secretion of insulin-like growth factor-1 and insulin-like growth factor binding proteins from differentiated skeletal muscle cells. J Biol Chem. 1995;270:2099-106.

45. Engler AJ, Sen S, Sweeney HL, Discher DE. Matrix elasticity directs stem cell lineage specification. Cell. 2006;126:677-89.

46. Lutolf MP, Blau HM. Artificial stem cell niches. Adv Mater. 2009;21:3255-68.

47. Lee DA, Knight MM, Campbell JJ, Bader DL. Stem cell mechanobiology. J Cell Biochem. 2011;112:1-9.

48. Li D, Zhou J, Chowdhury F, Cheng J, Wang N, Wang F. Role of mechanical factors in fate decisions of stem cells. Regen Med. 2011;6:229-40.

49. Wen JH, Vincent LG, Fuhrmann A, Choi YS, Hribar KC, Taylor-Weiner H, et al. Interplay of matrix stiffness and protein tethering in stem cell differentiation. Nat Mater. 2014;13(10):979-87. doi: 10.1038/nmat4051.

50. Wright WE, Sassoon DA, Lin VK. Myogenin, a factor regulating myogenesis, has a domain homologous to MyoD. Cell. 1989;56:607-17.

51. Bischoff R. Proliferation of muscle satellite cells on intact myofibers in culture. Developmental biology. 1986;115:129-39.

52. Pasut A, Jones AE, Rudnicki MA. Isolation and culture of individual myofibers and their satellite cells from adult skeletal muscle. J Vis Exp. 2013;22(73): e50074.

53. Kuang S, Kuroda K, Le Grand F, Rudnicki MA. Asymmetric self-renewal and commitment of satellite stem cells in muscle. Cell. 2007;129:999-1010.

54. Friden J, Lieber RL. Segmental muscle fiber lesions after repetitive eccentric contractions. Cell Tissue Res. 1998;293:165-71.

55. Tarone G, Lembo G. Molecular interplay between mechanical and humoral signalling in cardiac hypertrophy. Trends Mol Med. 2003;9:376-82.

56. Belkin AM, Retta SF, Pletjushkina OY, Balzac F, Silengo L, Fassler R, et al. Muscle beta1D integrin reinforces the cytoskeleton-matrix link: modulation of integrin adhesive function by alternative splicing. J Cell Biol. 1997;139:1583-95

57. Garcia-Alvarez B, de Pereda JM, Calderwood DA, Ulmer TS, Critchley D, Campbell ID, et al. Structural determinants of integrin recognition by talin. Mol Cell. 2003;11:49-58.

58. McGeachie JK. The fate of proliferating cells in skeletal muscle after denervation or tenotomy: an autoradiographic study. Neuroscience. 1985;15:499-506

59. Bentzinger CF, Rudnicki MA. Rejuvenating aged muscle stem cells. Nat Med. 2014;20:234-5
60. Irintchev A, Zeschnigk M, Starzinski-Powitz A, Wernig A. Expression pattern of M-cadherin in normal, denervated, and regenerating mouse muscles. Dev Dyn. 1994;199:326-37.

61. Marti M, Montserrat N, Pardo C, Mulero L, Miquel-Serra L, Rodrigues AM, et al. M-cadherin-mediated intercellular interactions activate satellite cell division. J Cell Sci. 2013;126:5116-31.

62. Cifuentes-Diaz C, Nicolet M, Alameddine H, Goudou D, Dehaupas M, Rieger F, et al. M-cadherin localization in developing adult and regenerating mouse skeletal muscle: possible involvement in secondary myogenesis. Mech Dev. 1995;50:85-97.

63. Bentzinger CF, Wang YX, von Maltzahn J, Soleimani VD, Yin H, Rudnicki MA. Fibronectin regulates Wnt7a signaling and satellite cell expansion. Cell Stem Cell. 2013;12:75-87.

64. Stoffels JM, Zhao C, Baron W. Fibronectin in tissue regeneration: timely disassembly of the scaffold is necessary to complete the build. Cell Mol Life Sci. 2013;70:4243-53.

65. Gulati AK, Reddi AH, Zalewski AA. Changes in the basement membrane zone components during skeletal muscle fiber degeneration and regeneration. J Cell Biol. 1983;97:957-62.

66. Gulati AK, Reddi AH, Zalewski AA. Distribution of fibronectin in normal and regenerating skeletal muscle. Anat Rec. 1982;204:175-83.

67. Engler AJ, Griffin MA, Sen S, Bonnemann CG, Sweeney HL, Discher DE. Myotubes differentiate optimally on substrates with tissue-like stiffness: pathological implications for soft or stiff microenvironments. J Cell Biol. 2004; 166:877-87.

68. Harris AR, Charras GT. Experimental validation of atomic force microscopy-based cell elasticity measurements. Nanotechnol. 2011;22:345102.

\section{Submit your next manuscript to BioMed Central and take full advantage of:}

- Convenient online submission

- Thorough peer review

- No space constraints or color figure charges

- Immediate publication on acceptance

- Inclusion in PubMed, CAS, Scopus and Google Scholar

- Research which is freely available for redistribution 